\title{
Cambio de paradigma médico y tuberculosis: México a la vuelta del siglo XIX
}

\author{
Enrique Rajchenberg $S$. \\ Facultad de Economía. \\ Universidad Nacional Autónoma de México. \\ México, D. F.
}

\begin{abstract}
A finales del siglo XIX, se difunden en México los descubrimientos realizados por Pasteur y Koch. La revolución microbiológica entraña, por una parte, una profunda modificación de la relación de la medicina con la comunidad científica dominada por las ciencias exactas y, por otra, una diferente explicación de la enfermedad tanto en los países de origen de los descubrimientos como en los países receptores. A través del análisis de la nueva mirada médica de la tuberculosis, el gran flagelo del siglo XIX, se puede reconstruir la concepción de la medicina acerca de la sociedad. El efecto social de la microbiología puede verificarse en sentido inverso: lejos de quedar confinada al ámbito de la comunidad científica, la microbiología deviene sustento legitimador de determinados actores sociales. El artículo demuestra el cambio de paradigma médico y de la mirada médica de los enfermos en México mediante la comparación de las tesis profesionales en medicina presentadas antes y después de los descubrimientos de la microbiología europea. Asimismo, verifica el uso social de la microbiología a través de la revisión de los argumentos esgrimidos por los empresarios industriales o sus abogados para rechazar las demandas crecientes de indemnización por los obreros en los años veinte de este siglo.
\end{abstract}

¿Qué es el diablo? el microbio que se agranda, ¿Y el microbio? es el diablo que se achica

\section{Pobres, tuberculosos y moralidad burguesa}

Aunque el romanticismo del siglo XIX nos legó una imagen de la tuberculosis con un halo de glamour, para la mayoría de la población, los primeros síntomas de la enfermedad implicaban el terror a la cercanía de la muerte inminente. No sólo los bohemios fallecían tuberculosos sino que el mal se extendía a segmentos amplios de la sociedad. Por ello, el siglo XIX es llamado el "siglo de la tuberculosis".

Al igual que durante las epidemias de cólera, la distribución desigual de la tuberculosis y de otros padecimientos indujo a algunos analistas sociales

1 Refrán citado por Melgarejo, Luis: Ensayo sobre el tratamiento de la tuberculosis, tesis para examen profesional de medicina, cirugía y obstetricia, Facultad de Medicina de México, 1889.

2 Laín Entralgo, Pedro: Historia de la medicina, Barcelona, 1978, pág. 512. Dice el mismo autor más adelante: "Durante todo el siglo XIX, pero sobre todo en sus décadas románticas, se vio en ella el arquetipo de "la enfermedad que distingue y mata"." 
europeos de procedencias científicas distintas a afirmar que existía un vínculo entre las condiciones materiales de existencia y la enfermedad. Engels, Virchow, Villermé son sólo algunos de los hombres ligados a esa preocupación. En su vertiente más radical, esta corriente evidenció las mutaciones que el novel proletariado urbano sufrió en su modo de vida al instaurarse el régimen de gran industria y desarrollarse la promiscuidad urbana. De estos análisis emergió un proyecto político que colocaba a la clase obrera como protagonista de la transformación de la sociedad. ${ }^{3}$ En otras palabras, del diagnóstico nacían los objetivos terapéuticos, integrales uno y otros.

Resulta obvio que esta concepción de la enfermedad poseía efectos peligrosos para la burguesía en tanto cuestionaba los logros económicos de la industrialización que, hacia mediados del siglo XIX europeo, se extendía a gran velocidad. La doxa liberal traducida a un código de conducta señalaba que el individuo se fabricaba su destino conforme a su conducta moral. Una de las expresiones de la concepción burguesa de la construcción individual del destino es la representación de la pobreza. Si hasta el siglo XVIII, el pobre es el Cristo que desciende a la tierra para verificar el respeto a las virtudes cristianas en el mundo terrenal, a partir del siglo XIX, el siglo de inauguración de la carrera desenfrenada por la ganancia individual, la pobreza cambia de signo. La exigencia de abolición de instituciones públicas de asistencia a los pobres va de la mano de la conversión de la caridad en un acto voluntario, cuya concesión o no pasa a ser un asunto saldado con la conciencia individual del benefactor y en absoluto una obligación ético-social. Por ello también, el pobre deja de ser el prójimo en desgracia para convertirse en miembro de una "raza", no de una clase, cuyos rasgos de salvajismo y barbarie la condenan a las calamidades que padece. ${ }^{4}$ Esta observación tiene claras expresiones en el México porfiriano:

"Coeficiente de barbarie, que sólo por una persistencia atávica de salvajismo en el espíritu de las masas inferiores se comprende...la producción del fenómeno criminológico indica, pues, que la causa es orgánica, y que la hiperestesia bélica e impulsatividad sanguinaria del salvaje persisten en esos delincuentes vulgares y se ponen en conmoción por hechos que son indiferentes para los demás". 5

3 Timio, Mario: Clases sociales y enfermedad. Introducción a una epidemiología diferencial, México, 1979, cap. I y Menéndez, Eduardo: "El modelo médico y la salud de los trabajadores" en Franco Basaglia et al., La salud de los trabajadores, México, 1978, págs 15-22. Paris, 1978.

4 Veáse sobre este punto, Chevalier, Louis: Classes laborieuses et classes dangereuses,

5 Citado por González Navarro, Moisés: "El porfiriato. La vida social" en Cossío Villegas, Daniel: Historia moderna de México, México, 1957, pág. 421. El texto original data de 1901. 
Sin embargo, los pensadores médico-sociales desbaratan la veracidad de este código demostrando, por un lado, el carácter colectivo de la enfermedad y, por otro, las determinaciones de ésta que, por lo tanto, están lejos de ser libremente escogidas. La situación no tardaría en cambiar.

La medicina hipocrática, cuya influencia se mantiene durante varios siglos, atribuye al clima una importancia particular en los estados mórbidos. El terreno, el agua, los alimentos, el modo de vida constituyen factores del estado sanitario de una región. En suma, "el hombre sano o enfermo es considerado parte integrante del conjunto cósmico". ${ }^{6}$ La explicación ambientalista de la enfermedad y de la salud da cuenta de los estados sanitarios colectivos y ofrece medios de curación individuales. Empero, desde principios del siglo XIX, el paradigma al cual deben ajustarse las ramas del conocimiento para gozar del estatuto de ciencia son las ciencias exactas. La concepción ambientalista de la salud y la enfermedad es demasiado vaga a los ojos del nuevo modelo científico: "La medicina ha sido rechazada durante mucho tiempo de las ciencias exactas", sentenció Bichat en 1801. "A partir de esas palabras, los médicos de vanguardia van a intentar con esforzado ahínco que sus juicios diagnósticos dejen de ser meramente conjeturales y precientíficos, y se hagan plenamente ciertos y científicos". ${ }^{7} \mathrm{Se}$ asiste en este terreno a una de las manifestaciones del choque, conceptualizado por Carlo Ginzburg, entre el paradigma de inferencias indiciales y el paradigma galileano. ${ }^{8}$ La cuantificación, el establecimiento de relaciones de causalidad, el principio epistemológico de conocimiento de la realidad como objeto, como cosa, la generalización, son algunas de las premisas del paradigma galileano. Todo aquel conocimiento que no se sujeta a ellas deja de ser considerado como verdadero y engrosa las filas de saberes y habilidades sin eficacia práctica aunque dignos de ser conservados junto con otras muestras del folklore. Sin embargo, la medicina, al igual que la historia, forman parte del conjunto de saberes que no renuncian a la particularidad de sus objetos-sujetos de estudio. Su adaptación al paradigma galileano tomará su tiempo.

En efecto, la culminación del esfuerzo de la medicina por alinearse con el desarrollo de las ciencias exactas sobrevendrá a finales del siglo XIX

6 Grmek, Mirko D.: "Géographie médicale et histoire des civilisations" en Annales, E.S.C. n. ${ }^{\circ}$ 6, noviembre-diciembre, París, 1963, pág. 1074.

7 Laín Entralgo: Historia de la..., pág. 514.

8 Ginzburg, Carlo: Mitos, emblemas, indicios. Morfología e historia, Barcelona, 1989, cap. 5: "Indicios", particularmente págs. 147-157. 
con los descubrimientos de Pasteur y Koch. En 1882, este último descubre el bacilo tuberculoso que lleva actualmente su nombre. La microbiología médica nacía y en su auge iría desplazando a las interpretaciones ambientalistas. La etiología de las enfermedades deja de ser social y recae exclusivamente en los microorganismos patógenos. De este modo, la medicina satisface una de las condiciones científicas, la de explicar mediante el establecimiento de una relación de causalidad exacta y objetiva:

"A instancias de la obra de Koch y de Pasteur, las concepciones acerca de la etiología de diversas enfermedades se vuelven más exactas y sobre todo más eficaces pero más estrechas. Se concede más importancia a las investigaciones sobre la biología de los gérmenes que al conocimiento de las influencias del medio".

Únicamente una postura ultraizquierdista señalaría a Pasteur y a Koch como ideólogos a sueldo de la burguesía quien, gracias a sus descubrimientos, se beneficia de la declinación del discurso médicosocial. En realidad, la ciencia recién empieza a forjar sus relaciones con la producción capitalista, ${ }^{10}$ aunque ciertamente la microbiología es retomada por el discurso burgués para denostar los amenazadores tonos de la medicina social hacia el orden y progreso capitalistas. No serían ya el establecimiento del régimen salarial, la industrialización capitalista y las condiciones de trabajo impuestas al proletariado los responsables de la tuberculosis, sino el bacilo de Koch. Es, en consecuencia, en el individuo aislado, atacado por un microorganismo anónimo, donde debe detenerse la mirada médica.

\section{Koch en México}

Los descubrimientos en microbiología tienen un fuerte impacto en México. Este efecto se advierte al confrontar los paradigmas explicativos de la tuberculosis pulmonar antes del descubrimiento realizado por Koch y después de este acontecimiento. Se puede comprobar dicha ruptura a través de las tesis en medicina sustentadas a fines del siglo XIX.

$\mathrm{El}$ tema de la tuberculosis interesa recurrentemente a futuros galenos y no es para menos. En el hospital de San Andrés en la ciudad de México,

9 Grmek: “Géographie médicale...”, pág. 1085.

10 Fueron la química y la física las que iniciaron esos nexos en la segunda mitad del siglo XIX a través de la aplicación de sus descubrimientos al proceso de producción inmediato de mercancías. La medicina no ingresaba aún al campo científico subsumido por el capital el cual en esa época sólo subsumía formalmente el proceso de reproducción de la fuerza de trabajo. 
entre 1874 y 1877 , de 545 tuberculosos ingresados, 347 fallecieron, de los cuales 295 era por tuberculosis pulmonar. La gravedad de la enfermedad se repetía en otros nosocomios. El doctor Vertiz señalaba que entre 1851 y 1877 el $56.03 \%$ de tuberculosos internados había fallecido. Ante este panorama, tanto para el común del pueblo como para el gremio médico, la tuberculosis significa el deceso inevitable. ${ }^{11}$

No obstante, la impotencia de los profesionales no impide que intenten explicar las causas de la enfermedad y ofrecer remedios empíricos. La pobreza y el hacinamiento urbano son declarados culpables de la enfermedad:

"La tisis se muestra principalmente en todas las personas sumidas en la miseria y cuyas habitaciones insalubres, mala alimentación y privaciones continuas, las ponen en la imposibilidad de precaverse de una manera eficaz contra las enfermedades. Lo que aparece de más positivo sobre la ethiología (sic) de esta afección es la herencia". ${ }^{12}$

Otro médico coincide con el anterior aunque discrepa justificadamente con respecto al carácter hereditario de la enfermedad. Retoma a Virchow para denunciar a la miseria: "La tuberculización debe existir donde exista la miseria, y miseria hay en todas partes". ${ }^{13}$ Igualmente están todos de acuerdo en lo excepcional de los casos curados:

"De los veinte ó veinticinco tísicos que habré observado directamente en el hospital, sólo uno he visto salir aliviado de la tisis: todos los demás los he visto terminar su carrera sobre la tierra, en la plancha del anfiteatro". ${ }^{14}$

Aunque se ignoran las razones, se sabe que Oaxaca registra pocos casos de tuberculosis. Ello es atribuido al clima y por esa misma razón había cundido la fama de los tuberculosos que se habían curado en la región.

Además de la recomendación de hallar un clima adecuado, los médicos aconsejan tónicos amargos, baños fríos, aceite de bacalao, hipofosfitos y fosfato de cal gelatinoso. Un médico observa que la tuberculosis es poco frecuente entre los alcohólicos y recomienda por lo tanto la ingesta de cognac.

11 Datos de alcance nacional de la tasa de mortalidad por tuberculosis a inicios del siglo XX en González Navarro, Moisés: Población y sociedad en México (1900-1970), México, 1974, págs. 364370 y para el porfiriato, del mismo autor, "El porfiriato. La vida social...", págs. 58-61.

12 Higareda, Alfredo: La tisis pulmonar, tesis para el examen profesional de medicina y cirugía, Escuela Nacional de Medicina, 1870, pág. 9.

13 Mejía, Demetrio: Tisis pulmonar. Su origen, unidad, asiento, estadística e influencia climatérica sobre su desarrollo y curación, 1879, pág. 35.

14 Higareda: La tisis pulmonar..., pág. 22. 
Pocos años después de escritos los textos reseñados, llega a México la noticia de la hazaña de Koch y suscita gran interés en las autoridades sanitarias alarmadas por la alta frecuencia del padecimiento en México y, particularmente, durante el último decenio del siglo. Por ello, un grupo de médicos del Consejo Superior de Salubridad se desplaza a Berlín en 1891 para conocer más detalles del descubrimiento de Koch..$^{15}$

A partir de ahí, se modifica la causalidad atribuida a la tuberculosis, así como las recetas médicas. "La Kochbacilosis, dice un pasante de medicina, es la soberana destructora de las masas". ${ }^{16}$ Reconoce el aspirante a galeno que la aglomeración en las grandes ciudades propicia la alta frecuencia de la tuberculosis, pero diluye en la alta densidad de población toda la problemática de miseria que los médicos prekochianos habían puesto de relieve.

En el mismo sentido, otro futuro médico indica que esta enfermedad "hiere en todas las edades, siega en todas las estaciones, es la enfermedad de la primavera de la vida, de la edad adulta y sobre todo de los grandes centros de civilización". ${ }^{17}$

Los medios terapéuticos recomendados cambian concomitantemente. El discurso médico adopta el tono moralista de la burguesía ante las prácticas consideradas viciosas de la población. Por consecuente debe descartarse ante todo el alcohol:

"Hay autores que creen que en los alcohólicos, no se desarrolla esta enfermedad; esta opinión no es muy aceptable, si tenemos en cuenta los desórdenes que se producen especialmente en los órganos digestivos por el abuso de los alcoholes". ${ }^{18}$

El autor de la tesis no aporta pruebas en torno a la ineficacia del alcohol para el tratamiento de la tuberculosis; simplemente condena su consumo. A cambio recomienda el arsénico, la estricnina, la glicerina y el cloruro de sodio, entre otros.

El bacilo de Koch constituye el pretexto para denunciar a la inmoralidad del populacho como legítimo responsable de la enfermedad, de la cual es su víctima favorita. De este modo, la medicina se erige en guardiana de las buenas costumbres en aguerrido combate contra el vicio. Desaparece de la medi-

15 González Navarro: "El porfiriato. La vida social...", pág. 61.

16 Hoyo, Javier: Algunas consideraciones acerca del tratamiento de la tuberculosis pulmonar de marcha crónica, tesis, Escuela Nacional de Medicina, 1899, pág. 18.

17 Melgarejo: Ensayo sobre el tratamiento..., pág. 9.

18 Santoyo, Rafael: Breve estudio sobre el tratamiento y profilaxia de la tuberculosis pulmonar, tesis, Facultad de Medicina de México, 1889, pág. 22. 
cina y de sus observaciones epidemiológicas primerizas la miseria popular como etiología colectiva de la enfermedad. Al referirse a los internos, un tesista señala que "con frecuencia se ve que los más jóvenes estudiantes adquieren vicios que, como el onanismo, además de ser altamente inmorales, son también altamente destructores del organismo". ${ }^{19}$ Por esta razón aconseja el seguimiento puntual de varias reglas a las que denomina "de higiene":

"Se procurará alejar del pueblo las costumbres alcohólicas, lo que se conseguirá:

A. Imponiendo castigos enérgicos al que quebrantara este precepto.

B. Elevando los impuestos á la venta de los alcoholes, tanto cuanto sea necesario para abolir, si fuere posible el expendio de dichas bebidas". ${ }^{20}$

Anexa recomendaciones de ventilación, alimentación y ejercicio para los internos de las escuelas y "además se cuidará de la moralidad de sus costumbres". ${ }^{21}$

Todavía aparecen adosadas a los consejos de buena conducta para evitar la tuberculosis, observaciones en torno a la elección de los climas benignos, mas este género de indicaciones queda opacado por las consideraciones que reciben el reconocimiento oficial de la academia científica. En esta última perspectiva, el bacilo de Koch penetra no los organismos debilitados por la miseria, sino aquellos corroidos por el vicio y la inmoralidad. Las recomendaciones de higienización de los pobres revisten el sentido de una moralización. Se recetan cambios en el "género de vida" sin que ello signifique el trastrocamiento de la condición de clase. Desde esta óptica, cambiar el género de vida se traduce por destierro de las costumbres inmorales $y$, entre éstas, destaca la embriaguez que tanto deplora la burguesía pues a ella le endilgan la indisciplina obrera, el ausentismo — los famosos San Lunes- y el bajo rendimiento de la fuerza de trabajo.

Con el tiempo, para algunos grupos obreros, el médico se convierte en purificador de las almas, conocedor al igual que el cura de las intimidades del pueblo y perseguidor de sus conductas oprobiosas:

"Este señor [el médico] es un Santo que nos quiere mucho y nos ayuda siempre con sus consejos separando del vicio a los que son tomadores". ${ }^{22}$

19 Cornejo, Antonio G.: La tuberculosis pulmonar en Guanajuato, Facultad de Medicina de México, 1894, pág. 37.

20 Ibídem, pág. 47.

21 Ibídem, pág. 48.

22 Archivo General de la Nación, Ramo Trabajo 732, 39, carta de los trabajadores de "The Mazappil Copper Co." al titular de la Secretaría de Industria Comercio y Trabajo, 2 de mayo de 1925. 
¿Acaso había logrado la medicina convencer a los pobres que la causa última de sus dolencias se encontraba en el fondo de las botellas de pulque?

\section{Conflictos obrero-patronales y tuberculosis: el bacilo de Koch como coartada}

He reseñado en otra parte cómo la incorporación de trabajadores de origen campesino y artesanal a la industria moderna en expansión a partir de 1890 implica el descubrimiento de realidades inéditas para el novel proletariado industrial. La disciplina del trabajo fabril, la sujeción estricta a horarios fijos y predeterminados, la regularidad de las labores, la compartimentación estricta entre tiempo de trabajo y tiempo libre son algunos de los descubrimientos de los obreros recién estrenados. ${ }^{23}$ Pero también asisten a la emergencia de una calamidad adicional: enfermedades ya conocidas o desconocidas para algunos cobran buen número de víctimas. Esto último no constituye una novedad en sí, sino el carácter colectivo de la enfermedad y de la muerte. Al inicio, los trabajadores enfermos ofrecen respuestas individuales como el retorno al lugar de origen para sanar o morir en la patria chica que los ha visto nacer o bien la añeja petición de una caridad o socorro al administrador para poder compensar la pérdida del ingreso monetario durante la convalecencia. En determinadas circunstancias, la solicitud de una caridad recibe el apoyo de los trabajadores en su conjunto, deja de ser una humilde petición y deviene una conflictiva exigencia colectiva.

El proceso de percepción de la patología emergente y su relación con las condiciones del trabajo industrial es lento. No obstante, el asociacionismo acelerado de los años revolucionarios - 1910-1920 - reduce, para algunos contingentes de trabajadores, los tiempos que toma este proceso. Las circunstancias políticas y, en no pocas ocasiones, el oportunismo político conducen a varios jefes revolucionarios, a la sazón gobernadores interinos o provisionales, a legislar sobre las condiciones de trabajo. En los nuevos códigos laborales queda asentada la responsabilidad patronal por los accidentes de trabajo y el consiguiente pago de una indemnización.

Puesto que el accidente acontece en horas de trabajo y en el lugar de trabajo, resulta sencillo determinar su profesionalidad. Ello no significa

23 Rajchenberg, Enrique: "Tradición e identidad: la clase obrera de Orizaba (1900- 1920)". Estudios Sociológicos n. ${ }^{\circ}$ 38, El Colegio de México, agosto 1995. 
que, en los primeros tiempos de la legislación laboral, las indemnizaciones sean pagadas automáticamente. Serán necesarias gestiones legales dilatadas ante diversas autoridades y la presión de la fuerza sindical para obtener las indemnizaciones e incluso así los esfuerzos a veces resultan infructuosos.

La enfermedad, a diferencia del accidente, no acontece en un momento determinado y en un lugar preciso. Los autores de los códigos del trabajo habían optado por dejar fuera la reglamentación de la indemnización de las enfermedades profesionales, así como la misma definición de la profesionalidad de la morbilidad obrera. Circunstancialmente, habían incluido el tema aunque en términos tan vagos que su aplicación se tornó imposible. ¿Cómo hacer valer entonces la profesionalidad de las enfermedades?

La frecuencia de determinada enfermedad en grupos relativamente homogéneos de trabajadores los conducirá, a pesar del vacío jurídico, a denunciar de manera torpe el vínculo entre las condiciones de trabajo y determinados padecimientos y a exigir el pago de indemnizaciones a los enfermos. Entre los mineros, es la silicosis; entre los textileros, la tuberculosis, aunque la movilización obrera no abarcará a los obreros de todas las regiones donde se localizan estas actividades productivas. Me detendré particularmente en la segunda enfermedad mencionada.

En la región que he estudiado más detenidamente - Orizaba y su hinterland fabril- es alrededor de los años 1918 y 1924 cuando se registra la mayor beligerancia obrera en torno a la profesionalidad de la tuberculosis. ${ }^{24}$ En este artículo, no interesa la exposición del desenvolvimiento de estos conflictos, sino la argumentación de los empresarios o de sus representantes ante las demandas obreras.

La inmoralidad de la raza de los obreros, sus hábitos etílicos y su desorden son denunciados por los empresarios y sus ideólogos para contrarrestar las exigencias de los trabajadores y culpabilizarlos de las desgracias tuberculosas que los aquejan. Por lo tanto, sería injusto, alegan, que ellos recompensen, mediante indemnizaciones, las conductas viciosas. Esta secular matriz discursiva no constituye ninguna novedad. Las tareas de moralización se imponen como remedio. Se trata de predicar el ahorro y el espíritu previsor para poder enfrentar individualmente al infortunio y de

24 Aunque ya se encontraba en la agenda reivindicativa de los obreros, la Ley del Trabajo de 1918 ofreció un marco de legalidad a la lucha por el reconocimiento de la profesionalidad de determinadas enfermedades y el pago de las indemnizaciones. Sin embargo, la ley era vaga puesto que no definía los criterios de profesionalidad de las enfermedades ni las enumeraba. Con ello abría las puertas al regateo y a la dilación de los pagos de indemnización. 
inducir un consumo menor de alcohol para acabar con el flagelo de la tuberculosis.

La novedad radica en la apropiación ideológica del nuevo descubrimiento de Koch para legitimar su rechazo a los ordenamientos legales y a las pretensiones obreras. El bacilo biologiza la causalidad de la tuberculosis $\mathrm{y}$, concomitantemente, le atribuye una causalidad socialmente neutral. En otras palabras, se escinde lo biológico de lo social: "La tuberculosis es una enfermedad peligrosa, señala el gerente de la fábrica de cigarros La Violeta en 1918, cuyos estragos se hacen sentir en todo el mundo, no importando que las personas tengan tal o cual ocupación profesional". ${ }^{25}$

El bacilo se convierte en la coartada para negar la profesionalidad de la tuberculosis. Puesto que la causa de la enfermedad pertenece al orden biológico, no hay razón para concluir que la tuberculosis posee determinaciones sociales. Las posibilidades teóricas de enfermar son idénticas en todos los individuos, pero si algunos se enferman más, ello se debe a un factor que asume el rango de variable independiente. Se trata de la inmoralidad de los pobres. Aquello que era denuncia de miseria social en el discurso de los médicos prekochianos deviene, en la argumentación burguesa, inmoralidad proletaria.

La burguesía reclama la demostración de una relación de causalidad perfectamente identificable, siguiendo el cánon de cientificidad exigido por el paradigma galileano. Retóricamente no puede negar su responsabilidad cuando acontecen accidentes en el trabajo porque la causa es una y su efecto inmediato es discernible. Pero está disconforme cuando se le achaca la responsabilidad por el bacilo de Koch.

Los trabajadores de Orizaba fueron tercos e insistieron en el reclamo de indemnizaciones para los tuberculosos o para sus deudos. El punto culminante de la lucha tiene lugar entre junio y julio de 1923 en una huelga que ha sido llamada "de los diez mil". ${ }^{26}$ Durante el paro, se escuchan los mismos argumentos desde que se había iniciado este reclamo:

"Querer hacer aparecer la tuberculosis pulmonar como una enfermedad profesional en los obreros de las industrias textiles, sería querer reducir por un simple decreto el

25 Citado por González Sierra, José: Monopolio del humo, Xalapa, 1987, pág. 170. Se trata de la respuesta a la reclamación de un obrero que contrae tuberculosis después de 14 años de trabajo en la fábrica. Por "humanitarismo", prosigue, se otorgará a los enfermos 4 pesos semanales durante tres meses, así como las medicinas necesarias.

26 Rajchenberg, Enrique: "Orizaba, junio de 1923: la huelga olvidada" en México entre dos revoluciones, México, 1993. 
radio de acción de uno de los más terribles azotes que sufre la humanidad. La tuberculosis es una enfermedad infecciosa producida por la invasión del organismo por el bacilus de Koch". ${ }^{27}$

El fin de la huelga es posible gracias, entre otros, a la promulgación de dos decretos sobre enfermedades. Uno concierne a las enfermedades "ordinarias" y el otro a las profesionales. Sin embargo, el gobierno del estado encarga la redacción de una ley sobre riesgos profesionales que defina a las enfermedades profesionales y el ámbito de responsabilidad patronal. Los empresarios se enteran del proyecto pero no logran conocer anticipadamente su contenido aunque si prevén que les será desfavorable. Por ello, contratan a especialistas cuyo dictamen no difiere de los argumentos de siempre: "La tuberculosis no puede ser considerada como enfermedad propia de alguna profesión, arte, oficio u ocupación alguna". ${ }^{28}$ Dos razones sustentan el razonamiento. La primera se refiere a la propagación del bacilo de Koch "desde el principio de la vida humana sobre toda la superficie de la tierra". Es una azote que aflige a toda la humanidad, no a un grupo particular de trabajadores. La segunda razón se basa en la predisposición del organismo. ¿Por qué, se preguntan, existen individuos con huellas de tubérculos que sin embargo no desarrollan la enfermedad? Esta evidencia permite concluir que la tuberculosis es causada, además del microbio, por

"la herencia, la debilidad congénita, la acumulación de hogares estrechos, poco iluminados y menos ventilados, la escasa alimentación, las enfermedades debilitantes, el alcoholismo y la sífilis de los padres, el alcoholismo de los mismos individuos, la diabetes". ${ }^{29}$

Por todo lo anterior, la tuberculosis posee "un origen extraprofesional" y está "totalmente fuera del alcance de su (del patrón) responsabilidad". ${ }^{30}$

A pesar de la campaña preventiva, en julio de 1924, la ley es aprobada. El temor patronal estaba justificado. En su exposición de motivos, se señala que

"en la presente ley se consideran todas las enfermedades cuyo carácter profesional se ha reconocido por las primeras autoridades científicas y entre dichas enfermedades se

27 El Dictamen, Veracruz, 10 de julio de 1923.

28 Archivo de la Compañía Industrial de Orizaba, 24 de octubre de 1923, sin clasificación, Río Blanco, Veracruz.

29 Ibídem.

30 Ibídem. 
ha incluido la tuberculosis, porque si bien es cierto que ataca a cualquier persona, sea o no trabajador, también lo es que los polvos, principalmente, son causas indiscutiblemente de ella". ${ }^{31}$

La legislación veracruzana se vuelve motivo de escándalo y denuncia en las cámaras industriales. Los gastos originados por la legislación han aumentado desmesuradamente, afirman. La nueva disposición legal suprime la generosidad patronal ejercida desde mucho tiempo atrás sin necesidad de métodos coercitivos y la suplanta por "el aprovechamiento, por toda clase de beneficiarios, del abuso de la responsabilidad patronal"; 32 por ello pregunta el autor del artículo:

“¿Hice bien con haber establecido de modo espontáneo y sin que nada ni nadie me obligara, un servicio médico y farmacéutico para mis trabajadores y sus familiares realmente enfermos, siendo que este acto que yo quise orientar noblemente se ha convertido en obligación?" ${ }^{3}$

El reconocimiento de la profesionalidad de la tuberculosis constituye el otro punto que suscita indignación entre los industriales. Ninguna legislación extranjera ni obra científica, aseveran, la habían mencionado como enfermedad profesional. El bacilo de Koch sigue siendo la coartada, sin embargo, un cambio se ha operado. Los obreros ya no son designados, por lo menos públicamente, como una raza salvaje, sino que deben ser reconocidos como una clase convertida en interlocutora social de los empresarios.

La Convención Industrial del Ramo Textil que se reúne a partir del 6 de octubre de 1925 es la ocasión para que los empresarios vuelvan a plantear el problema:

"Por lo que hace a la industria textil debemos decir que no se han señalado enfermedades profesionales peculiares a esta industria, en ninguna de las legislaciones del mundo, ni aun en aquellos países en donde esta rama industrial ha adquirido un gran desarrollo; en la industria textil sólo podrían señalarse aquellos casos de intoxicación ocasionados por razón de los materiales que se manejan, especialmente en los departamentos de Tintorería y Estampado". ${ }^{34}$

31 Proyecto de ley sobre riesgos profesionales, mimeo.

32 "La legislación veracruzana sobre responsabilidad patronal en las enfermedades de los obreros" en México industrial, México, octubre de 1925, pág. 213.

33 Ibídem, México industrial, diciembre de 1925, pág. 254 (subrayado del autor).

34 Robredo, José: Puntos de vista de los industriales de hilados y tejidos de la República sobre los asuntos puestos a discusión en la Convención Industrial Obrera del ramo Textil, México, 1925, pág. 60. 
Definitivamente, la tuberculosis debe ser considerada una enfermedad ordinaria, "desgraciadamente muy extendida y que no se adquiere por el solo trabajo en la industria textil". ${ }^{35}$ Durante la Convención, los patrones logran que, a falta de derogar el artículo sobre enfermedades profesionales de la legislación veracruzana, se prohíba la admisión de trabajadores tuberculosos a las fábricas textiles. ${ }^{36}$

La revancha llegaría en 1931 cuando entra en vigor la Ley Federal del Trabajo. Esta no contempla el pago del salario a los enfermos "no profesionales" ni tampoco reconoce a la tuberculosis como padecimiento profesional para los trabajadores textiles.

35 Ibídem. Todavía en 1928 se oiría la misma argumentación sobre la tuberculosis: "En la Ley de Riesgos Profesionales del Estado de Veracruz se alarga excesivamente el concepto de enfermedad profesional (...). Hace posible la clasificación de cualquier enfermedad ordinaria como enfermedad profesional". Camiro, Maximiliano: Las leyes del trabajo en México, México, 1928, pág. 19. El autor había representado a la fábrica Río Blanco en los litigios por demanda de indemnización desde 1918. Posteriormente representó a la fábrica Cerritos en la Convención de 1925.

36 Secretaría de Industria, Comercio y Trabajo: Convención colectiva de trabajo y tarifas mínimas de aplicación en la República, México, 1927, pág. 44. 